\title{
Definition of Mechanical Indicators of Plastic Details of the Oil-Field Equipment
}

\author{
N. A. Gasanova
}

\begin{abstract}
The analysis of the manufacture of plastic details of the oil-field equipment was made, which made it possible to establish the regularity of the shrinkage change of plastic details from the regimes of their production. Changes of quality of ready details depending on casting pressure are defined, and the regularity of the change in shrinkage, density, ruggedness, hardness, breaking stress at distension from regimes of casting is established.
\end{abstract}

KEYWORDS- Manufacturing process, Oil-field equipment, Optimal pressure, Press form, Technological parameters

\section{INTRODUCTION}

The question of the quality of details of oilfield equipment is one of the pressing problems of modern scientific and technological development. Especially this problem is important for parts manufactured from structurally non-uniform heterogeneous materials, such as plastics, which are widely used in petroleum equipment. The quality of plastic details is formed, basically, in the process of their manufacture. Therefore, it is very important to control the stability of process parameters in the manufacturing process. If in a ready detail in most cases the found defects and deviations of some parameters of material don't manage to be eliminated, then in the course of production the revealed deviations can be eliminated in due time due to change of the technological regimes [1].

\section{TECHNOLOGICAL PARAMETERS OF PROCESS OF PRODUCTION OF PLASTIC DETAILS OF THE OIL-FIELD EQUIPMENT}

The character of the course of physical and chemical processes, formation of structure and properties of plastic, generally depends on technological parameters of process of production of concrete details.

Towards the main technological parameters for the casting of thermo reactive materials under pressure are included: temperature of the cylinder Tc, speed of heating and cooling, temperature of a form $\mathrm{Tf}$, pressure of fusion $\mathrm{P}$, delay time in the form under pressure $t$, delay time of fusion without pressure t0. Variation and management of these

Manuscript received July 24, 2020

N. A. Gasanova, Doctor of Philosophy on Technique, Azerbaijan State Oil and Industry University, Baku, Azerbaijan Republic (e-mail: gunaycabirqizi@gmail.com) parameters depending on brand of materials leads to essential change of quality $(\sigma \mathrm{p}, \sigma \mathrm{t}, \sigma \mathrm{w}, \mathrm{Q}, \mathrm{Rz})$ of manufactured, especially interfaced details of [2].

\section{PRESSURE UPON FUSION AS THE MAIN REGIME PARAMETER}

For example, from the main regime parameters the pressure in the time of casting the details from thermoplastic plastics is necessary for filling of the mold-press compression shaping cavity, with the fusion material, his compacting and also for normal course of relaxation processes at the cooling in shape, i.e. the main regime parameter is pressure of fusion. It is established that the numerical value of optimum pressure upon casting depends on brand of material, volume of details and their thickness and a configuration. In practice, the pressure ranged from $66 \mathrm{MPa}$ to $114 \mathrm{MPa}[3,4]$.

\section{EXPERIMENT RESULT}

For studying of influence of pressure upon fusion we conducted a research of this influence on quality of plastic details.

In fig. 1, a show the curves dependence of shrinkage ( $\mathrm{Sb}$ ), density $(\rho)$ and roughness of surface $(\mathrm{Ra})$ material of ABC-plastic from the pressure on the fusion in the cylinder. From the analysis of the curves of the dependences shown in Fig. 1, it is seen that with increase in pressure of fusion the density of material increased $(\rho)$, shrinkage (Sb) decreased, and the roughness of a surface ( $\mathrm{Ra}$ ) strongly falls,

It should be noted that these indicators need to be considered when using this material in designs of the loaded details working in various atmospheric conditions, in elements of the oil-field equipment.

From curves of dependence of hardness and bursting stress at tension of details from ABS plastic material from pressure it is seen that with increase in pressure of fusion from 60 to $115 \mathrm{MPa}$ the hardness of samples increases and reaches the maximum value. The same regularity is observed also when studying character of a bursting stress at stretching, i.e. with a pressure of fusion of $65 \mathrm{MPa}-\sigma \mathrm{s}=$ $86 \mathrm{MPa}$, and at $105 \mathrm{MPa}-\sigma \mathrm{s}=43,1 \mathrm{MPa}$, with increase in density $\rho$ durability begins to decrease.

This phenomenon is explained by the fact that at high pressures the material in the cylinder is uniformly compacted, i.e. the homogeneity of the fusion is almost guaranteed, and as a result shrinkage decreased, and the density increased (a curve 2 in Fig.1, b) 

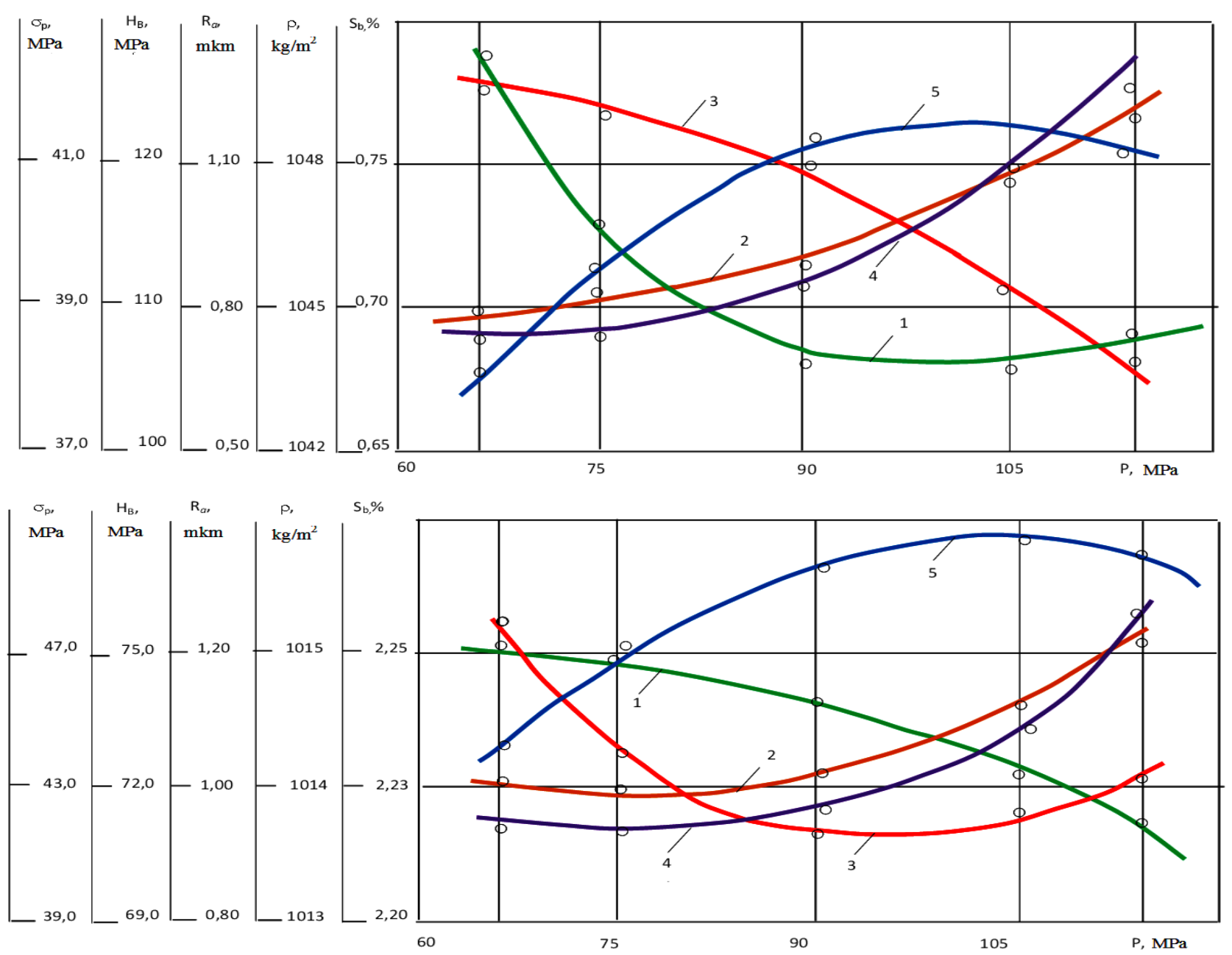

Fig.1: Schedule of dependence of shrinkage (1), density (2), roughness of a surface (3), hardness (4), breaking point at stretching (5) details from ABC-plastic (a), from polyamide (b) from pressure

Simultaneously, the surface roughness of details and samples is decreased. This again confirms the regularity that at high pressures on the fusion in the cylinder, while the material is not spread out, uniform compacting occur, homogeneity of the material in the cylinder is ensured, and as a result, the quality of the parts is increased [5].

At consideration of curves of dependence of the hardness $\mathrm{HB}$ and bursting stress $\sigma \mathrm{s}$ (see the fig.1, b) it is seen that with increase in pressure on fusion $(\mathrm{P})$ the hardness and a bursting stress increased, i.e. at $\mathrm{P}=70 \mathrm{MPa}$, hardness is $79 \mathrm{MPa}$, a bursting stress - $44 \mathrm{MPa}$. Hereinafter with increase in pressure both indicators reaches the maximum value, i.e. $\mathrm{HB}=78 \mathrm{MPa}$ and $\sigma \mathrm{s}$ $=51 \mathrm{MPa}$.

\section{CONCLUSION}

With big pressures in the cylinder a material of fusion is quickly filled in a cavity of a compression press-mold and uniform internal stress at cooling, in the press-mold solidification of a material happens, through the sections (from edges to the center) that promotes increase in hardness and a bursting stress of details.

\section{REFERENCES}

[1] Kerimov D.A. Kurbanova S.K. Bases of designing of plastic details and press-moulds. Baku: Publishing house "Elm", 1997, 504 pages.

[2] Bronfeld G.B., Mikhaylov A.V. Modeling of management process by quality of products from plastic. - In book: Quality of plastic and reliability of products made of them. - L. : LDNTP, 1976

[3] Gabibov I.A. Role of a design of products in formation of structure of thermo thermoplastics when casting under pressure. Thesis of Cand.Tech.Sci. - M.: MHTXT of Lomonosov, 1984

[4] Kerimov D.A., Gasanova N.A. Development of optimal regimes of cooling for plastic parts of thermosets. SAEQ Science \& Applied Engineering Quarterly, Jan-Feb-Mar 2017, p. 17-19

[5] Gasanova N.A. Behavior of plastic working in oil-field equipment. International Journal of Innovative Research in Computer Science \& Technology (IJIRCST). ISSN: 2347-5552, Volume 5, Issue 5, September 2017 